\title{
The 2022 Virtual Workshop on Statistical Genetic Methods for Human Complex Traits: Advance Notice June 6th-June 16th, 2022
}

๑) Springer Science+Business Media, LLC, part of Springer Nature 2021

We have elected to hold the 2022 workshop virtually, with plans to hold the 2023 course in-person in Boulder, CO. We have made this decision based on the success of last year's workshop, the desire to continue to build our library of online content, the enhanced ability to reach a larger pool of students, and the continued uncertainty regarding travel due to the COVID-19 pandemic. Like last year, we will hold the workshop at the beginning of June (June 6-16, 2022). Because last year's workshop focused more heavily on measured genetics and genetic association, this year's workshop will focus more heavily on latent genetic analyses, structural equation modeling, and twin/family designs.

Like last year, the daily schedule will include prerecorded lectures, plenary sessions, practical work, and interactive tutorials. Registered students will need to be able to commit approximately $2 \mathrm{~h}$ per day for watching pre-recorded videos and $3 \mathrm{~h}$ per day for live lecture and practical work for each of the 8 days of the workshop. Pre-recorded lectures will be available for viewing one week before the start of the course. The workshop will be held 4 days per week (Monday-Thursday, US) across 2 weeks: June 6-9 and June 13-16. As with last year, participants will be able to sign up for one of two course tracks that differ only in the time of day of presentations and tutorials: one meant to be most convenient for students in Europe/Africa/Americas (track A) and one most convenient for students in Western North America/Asia/Australia/Oceania (track B).

Topics will include: the biometrical model, structural equation modeling, path analysis, maximum likelihood, univariate twin models, sex limitation, GxE interaction, segregation variance, polygenic scores, assumptions in twin models and effects of violating those assumptions, genetic nurture and $G$-E covariance, multivariate genetic analyses, and longitudinal models. Software will include R, OpenMx, PLINK, and GCTA.

Participants are strongly advised to have some familiarity with R programming before attending the workshop. Students not familiar with $\mathrm{R}$ can take advantage of an $\mathrm{R}$ tutorial we will post before the workshop or any number of introductory R tutorials available online. Students will use workshop facilities for practical work but will need their own desktop or laptop computer to connect to the workshop resources.

The Academic Directors for this workshop are:

Ben Neale (Broad Institute and Massachusetts General Hospital (MGH)),

Dave Evans (Institute for Molecular Bioscience, University of Queensland (UQ), Australia),

Sarah Medland (Queensland Institute for Medical Research (QIMR), Australia),

Michael Neale (Virginia Institute for Psychiatric and Behavioral Genetics, Virginia Commonwealth University).

The local hosts for this workshop are at the Institute for Behavioral Genetics:

Matthew Keller (Principal Investigator)

Jeffrey Lessem (IT director)

Courtney Greenwood (local coordinator; IBGworkshop@colorado.edu).

In addition to the academic directors and hosts, faculty will include Conor Dolan, Hermine Maes, Brad Verhulst, Katrina Grasby, Lucia Colodro Condre, and Elizabeth PromWormley, who will offer world-class instruction on the topics listed above and who will help students work through practical sessions in real time.

Registration will open January 31. The registration fee will be $\$ 300$, payable at the time of registration using a credit card. Cancellations after April $15^{\text {th }}$ will be nonrefundable. We will make another announcement in midJanuary with details about scheduling, registration, and course materials. This information will also be available at https://www.colorado.edu/ibg/workshop-2022 or from the 
workshop coordinator: tel: + 1-303-735-8490; e-mail: IBGworkshop@colorado.edu.

Individuals from underrepresented racial and ethnic groups, individuals with disabilities, and individuals from socially, culturally, economically, or educationally disadvantaged backgrounds are especially encouraged to attend. Financial support for US participants from these groups is available by application to the local host, Matthew Keller.
Contact the workshop coordinator, Courtney Greenwood, for more information regarding financial support.

Financial support for this workshop is provided by grant MH19918 from the National Institute of Mental Health.

Publisher's Note Springer Nature remains neutral with regard to jurisdictional claims in published maps and institutional affiliations. 